\title{
Galanin receptor 2 mediates antifibrogenic effects of galanin on hepatic stellate cells
}

\author{
LINGNAN HE $^{1 *}$, ZHENGHONG LI $^{1 *}$, DA ZHOU ${ }^{1}$, YONGNIAN DING $^{2}$, LEIMING XU ${ }^{1}$, \\ YUANWEN CHEN $^{1}$ and JIANGAO FAN ${ }^{1}$ \\ ${ }^{1}$ Department of Gastroenterology, Xinhua Hospital, Shanghai Jiaotong University School of Medicine, Shanghai 200092; \\ ${ }^{2}$ Department of Gastroenterology, Second Affiliated Hospital of Xinjiang Medical University, \\ Urumqi, Xinjiang 830028, P.R. China
}

Received July 19, 2015; Accepted September 9, 2016

DOI: $10.3892 /$ etm.2016.3764

\begin{abstract}
Galanin is an endogenous factor involved in the negative regulation of the biological effects of leptin in bioenergetic metabolism. Leptin promotes fibrogenic effects in hepatic stellate cells (HSCs), however, little is known about the effects of galanin on HSCs. In the present study, the biological functions of galanin and its receptors (GalRs) in HSCs were investigated using cell culture in vitro. It was found that galanin and GalR3 mRNA are expressed in quiescent and activated HSCs. GalR2 expression was undetectable in quiescent HSCs but was markedly induced in activated HSCs. In the HSC-T6 cell line, which is an activated rat HSC cell line, treatment with $100 \mathrm{nmol} / 1$ galanin significantly inhibited cell proliferation. It also inhibited transforming growth factor (TGF)- $\beta 1$ and $\alpha$-smooth muscle actin (SMA) expression and upregulated peroxisome proliferator-activated receptor (PPAR)- $\gamma$ expression. Following the knockdown of GalR2 by specific small interfering RNA, the activation of GalR3 by galanin does not influence these effects of galanin on HSCs. However, activation of GalR2 alone by galanin following the knockdown of GalR3 inhibits HSC proliferation and TGF- $\beta 1$ and $\alpha$-SMA expression, in addition to inducing PPAR- $\gamma$ expression. These data suggest that galanin inhibits HSC activation and suppresses the profibrogenic features of these cells, and these effects might be mediated by GalR2. Thus, galanin is a potential endogenous factor in the inhibition of liver fibrosis.
\end{abstract}

Correspondence to: Dr Yuanwen Chen, Department of Gastroenterology, Xinhua Hospital, Shanghai Jiaotong University School of Medicine, 1665 Kongjiang Road, Shanghai 200092, P.R. China

E-mail:shsmus@263.net

*Contributed equally

Key words: galanin, hepatic stellate cells, receptor, transforming growth factor- $\beta, \alpha$-smooth muscle actin, peroxisome proliferator-activated receptor- $\gamma$

\section{Introduction}

Galanin is a 29 -amino acid peptide naturally present in the tissues and fluids of humans and animals (1). To date three galanin receptors (GalR1, GalR2 and GalR3) have been discovered to be widely distributed in the mammalian central and peripheral nervous system (2). It is acknowledged that galanin has a critical role in the regulation of energy homeostasis (3). Leptin, another adipocyte-derived hormone, is also a key factor in the regulation of body weight and energy expenditure and acts in rodents via hypothalamus receptors to inhibit feeding and increase thermogenesis (4). Notably, a previous study confirmed that galanin inhibits leptin expression and secretion in rat adipose tissue and 3T3-L1 adipocytes (5). Leptin has been shown to possess direct profibrogenic activity in the liver, and the absence of leptin is associated with a marked attenuation of the hepatic response to a diverse range of fibrotic stimuli (6). It has been hypothesized that leptin acts directly on hepatic stellate cells (HSCs) to trigger downstream response pathways that ultimately lead to the deposition of extracellular matrix (ECM) (7). However, little is known about the effects of galanin on HSCs. Since the activation and proliferation of HSCs are the key factors in the progress of liver fibrosis, in view of the counteracting effect of galanin on leptin in food intake and energy metabolism, the effect of galanin on the proliferation of HSCs becomes an interesting research topic.

It may be hypothesized that galanin is able to inhibit the activation and proliferation of HSCs. In the present study, to test this hypothesis, the galanin and GalR mRNA expression in quiescent and activated HSCs was first examined. The effects of galanin and GalRs on the proliferation and secretion of HSCs were also explored.

\section{Materials and methods}

Animals. A total of 3 male Sprague-Dawley rats (230-300 g; 7-8 weeks-old) were obtained from the Shanghai Experimental Animal Center (Shanghai, China). All rats were maintained in cages under pathogen-free condition on a 12-hour light/12-hour dark schedule, and had ad libitum access to water and food. All animal handling and experimental procedures were approved 
by the Animal Care and Use Committee of the Shanghai Jiaotong University School of Medicine (Shanghai, China).

Primary HSC isolation. HSCs were isolated from the male Sprague-Dawley rats (375-400 g) as described previously (8). Briefly, the rat liver was perfused in situ with D-Hanks buffer for $5 \mathrm{~min}, 0.02 \%$ pronase for $5 \mathrm{~min}$ and $0.04 \%$ collagenase (type IV) for $10 \mathrm{~min}$ at a flow rate of $5 \mathrm{ml} / \mathrm{min}$. Following in situ digestion, the liver was removed, minced and further digested with $0.08 \%$ collagenase at $37^{\circ} \mathrm{C}$ for $30 \mathrm{~min}$. The cell suspension was carefully layered on top of two layers $(6 \%$ and $10 \%$ ) of OptiPrep Density Gradient Medium (Sigma-Aldrich; Merck Millipore, Darmstadt, Germany). After centrifugation at $1400 \mathrm{x} \mathrm{g}$ for $20 \mathrm{~min}$, the cells from the interface were collected and were used as primary HSCs. Isolated HSCs were suspended in Dulbecco's modified Eagle's medium (DMEM; Sigma-Aldrich; Merck Millipore) supplemented with 10\% fetal bovine serum (FBS; Gibco; Thermo Fisher Scientific, Inc., Waltham, MA, USA) (10\% FBS/DMEM), $100 \mathrm{IU} / \mathrm{ml}$ penicillin and $100 \mathrm{mg} / \mathrm{ml}$ streptomycin (all Gibco), and were plated at $2 \times 10^{5}$ cells $/ \mathrm{cm}^{2}$ on non-coated 6-well plastic plates (Costar; Corning Incorporated, Corning, NY, USA). HSCs were cultured for 7 days in vitro and were used as fully activated HSCs. Cell purity was $95 \%$ as determined by examination of morphology and vitamin A autofluorescence.

Reverse transcription-polymerase chain reaction (RT-PCR). Total RNA was extracted from HSCs using TRIzol reagent (Thermo Fisher Scientific, Inc.) according to the manufacturer's protocol. Total RNA from rat hypothalamus was used as a positive control. Total RNA was subjected to DNase (Invitrogen; Thermo Fisher Scientific, Inc.) treatment prior to reverse transcription. For RT-PCR, $1 \mu \mathrm{g}$ total RNA was reverse transcribed with Moloney murine leukemia virus reverse transcriptase (M-MLV; Santa Cruz Biotechnology, Inc., Dallas, TX, USA) according to the manufacturer's instructions. cDNAs were then amplified using specific sets of primers for each gene. Taq DNA polymerase purchased from Promega Corporation was used for PCR. The amplification cycle numbers for Galanin, GalR1, GalR2 and GalR3 were $40,37,37$ and 40, respectively. The sequences of each pair of primers, product sizes and amplification conditions are listed in Table I. In parallel, PCR was performed with primers coding for GAPDH to control for equal amounts of template cDNAs. Analysis was conducted using 5-20 $\mu$ l total PCR product in a $2.5 \%$ agarose gel. The gels were scanned using a densitometer (Furi Science \& Technology Ltd., Shanghai, China). Primer specificity was confirmed with sequencing of PCR products.

Immunofluorescence. The HSC-T6 cell line, which is an immortalized rat liver stellate cell line that has a stable phenotype and biochemical characteristics compared with primary stellate cells (9), was obtained from the Chinese Academy of Sciences (Shanghai, China). HSC-T6 cells were seeded in a 4-well cell culture chamber in 10\% FBS/DMEM at $2 \times 10^{3}$ cells $/ \mathrm{cm}^{2}$. The culture medium was changed daily and cells were fixed in ice-cold $4 \%$ paraformaldehyde after 3 days. After further washes, cells were incubated at room temperature for 30 min with TBS containing $10 \%$ goat serum and $1 \%$ bovine serum albumin (both purchased from Vector
Laboratories, Burlingame, CA, USA) to prevent non-specific binding of primary antibody. For GalR2 staining, fixed HSC-T6 cells were incubated with anti-GalR2 goat polyclonal antibody (cat. no. ab59029; Abcam, Cambridge, MA, USA; 1:100 dilution) at $4^{\circ} \mathrm{C}$ overnight followed by incubation with fluorescein isothiocyanate-conjugated secondary antibodies (cat. no. ab150141; Abcam, Cambridge, MA; 1:100 dilution) at $37^{\circ} \mathrm{C}$ for $2 \mathrm{~h}$. A negative control without primary antibody staining was included.

Cell proliferation assay. HSC-T6 cells were seeded on 94-well plastic plates in $10 \% \mathrm{FBS} / \mathrm{DMEM}$ at $2 \times 10^{3} \mathrm{cells} / \mathrm{cm}^{2}$. At 3 days after seeding, HSCs were serum-starved for $24 \mathrm{~h}$ in $2 \% \mathrm{FBS} / \mathrm{DMEM}$ and then subjected to treatment with galanin (Sigma-Aldrich) at concentrations of $1-10,000 \mathrm{nmol} / \mathrm{l}$ for $24 \mathrm{~h}$. Cell proliferation was measured using an MTT assay. A working concentration of galanin $(100 \mathrm{nmol} / \mathrm{l})$ was identified and used for the following experiments.

Small interfering RNA (siRNA) transfection and cell treatment. The siRNAs against mouse GalR2 and GalR3 mRNA were designed and synthesized by Life Technologies (Thermo Fisher Scientific, Inc.). The most effective one was selected for the construction of the siRNA expression vector. The siRNAs had the following sequences: GalR2-siRNA, forward: 5'CUCCAAGCAUUUCCGUAA AdTdT3' and reverse: 5'UUUACGGAAAUGCUUGGA GdTdT3'; GalR3-siRNA, forward: 5'CCUCGCACUGCC UCGCCUAdTdT3' and reverse 5'UUAGUCUAGUCUCUC CACCdTdT3'. Scrambled siRNA (forward 5'GCTCATATT ACCAGTCACATT3' and reverse 5'GAGGTGGATCGATTT ATTCTA3') was also chemically synthesized and served as a negative control to assess non-specific gene silencing effects (Life Technologies). HSC-T6 cells were transfected with a mixture of plasmid DNA and Lipofectamine 2000 (Life Technologies) in Opti-MEM I medium without serum as recommended by the manufacturer. The medium was later replaced with standard RPMI 1640 medium (containing 10\% FBS; Sigma-Aldrich; Merck Millipore). Cultured HSC-T6 cells were divided to four groups: Control, galanin treatment group (galanin $100 \mathrm{nmol} / \mathrm{l}$ ), GalR2 siRNA treatment group (GalR2 siRNA + galanin) and GalR3 siRNA treatment group (GalR3 siRNA + galanin). The proliferation of HSC-T6 cells was measured using an MTT assay.

Western blot analysis. Cultured HSC-T6 cells were homogenized in ice-cold radioimmunoprecipitation assay buffer containing protease and phosphatase inhibitors (Beyotime Biotechnology, Shanghai, China). Western blotting was performed as previously described (10). The mouse antibodies anti- $\alpha$-smooth muscle actin ( $\alpha$-SMA; cat. no. ab18147; 1:2,000 dilution), anti-transforming growth factor (TGF)- $\beta 1$ (cat. no. ab64715; 1:2,000 dilution), anti-peroxisome proliferator-activated receptor (PPAR)- $\gamma$ (cat. no. ab41928; 1:1,000 dilution) and anti- $\beta$-actin (cat. no. ab8226; 1:3,000 dilution) were obtained from Abcam (Cambridge, MA, USA), and secondary horseradish peroxidase-conjugated goat anti-mouse IgG antibody (cat. no. A9917; 1:60,000 dilution) was purchased from Sigma-Aldrich (Merck Millipore). Protein bands were quantified with Bio-Rad Image Lab 2.0 software (Bio-Rad 
Table I. PCR primers, annealing temperature and amplicon size of galanin and galanin receptors.

\begin{tabular}{|c|c|c|c|}
\hline Gene & Sequence & Annealing $\mathrm{T}\left({ }^{\circ} \mathrm{C}\right)$ & Size (bp) \\
\hline Galanin & $\begin{array}{l}\text { Foward: 5'-TACCCCTGCCTGAGAGCAAT-3' } \\
\text { Reverse: 5'-TCTTCTGAGGAGGTGGCCAA-3' }\end{array}$ & 61 & 118 \\
\hline GalR1 & $\begin{array}{l}\text { Foward: 5'-TGCTTTTGCTATGCCAAGGTTC-3' } \\
\text { Reverse: 5'-TCGGTTCTTTTCTTTAGCATCGC-3' }\end{array}$ & 61 & 359 \\
\hline GalR2 & $\begin{array}{l}\text { Foward: 5'-TTCTGCCTCTGTTGGATGCC-3' } \\
\text { Reverse: 5'-TCTACTCGAGGCTGTGCAGTTG-3' }\end{array}$ & 58 & 362 \\
\hline GalR3 & $\begin{array}{l}\text { Foward: 5'-AGCCAAGCAGTACCACAGAT-3' } \\
\text { Reverse: 5'-GGTGAGGTAGATGAGCAGAT-3' }\end{array}$ & 62 & 161 \\
\hline GAPDH & $\begin{array}{l}\text { Foward: 5'-CATGGTCTACACGTACCAGT-3' } \\
\text { Reverse: 5'- GGCAAGCAGTI'GGTGGTGC-3' }\end{array}$ & 58 & 349 \\
\hline
\end{tabular}

PCR, polymerase chain reaction; GalR, galanin receptor.

Laboratories, Inc., Hercules, CA, USA). $\beta$-actin was used as the loading control.

Statistical analysis. Results were expressed as mean \pm standard error of the mean. At least three independent experiments were performed for each experiment. Data were analyzed by Student's t-test or one way analysis of variance followed by Mann Whitney U test using the SAS system (release 8.02, TS level 02M0; SAS Institute, Cary, NC, USA). P<0.05 was considered to indicate a statistically significant result.

\section{Results}

Differential expression patterns of galanin and GalRs in quiescent and activated HSCs. The expression levels of galanin and GalRs were evaluated using RT-PCR, and it was found that galanin and GalR3 mRNA are expressed in both quiescent and activated HSCs while GalR2 mRNA is undetectable in quiescent HSCs but is highly expressed in activated HSCs. GalR1 mRNA was undetectable in both quiescent and activated HSCs (Fig. 1A). The expression of GalR2 protein in cultured HSC-T6 cells was confirmed using immunofluorescence staining (Fig. 1B).

Galanin and GalRs regulate HSC proliferation and profibrogenic protein expression. Whether galanin and its receptors have roles in HSC proliferation and the profibrogenic process was next investigated. HSC-T6 cells were treated with different concentration of galanin ranging from 1-10,000 $\mathrm{nmol} / \mathrm{l}$ and it was found that 100 and $1,000 \mathrm{nmol} / 1$ galanin significantly inhibited the proliferation of HSCs. The $100 \mathrm{nmol} / 1$ concentration of galanin showed the most marked inhibitory effect (Fig. 2A). To study the roles of GalRs on HSC growth, GalRs were depleted in HSC-T6 cells using siRNA and it was found that GalR2 knockdown did not have a notable effect on cell proliferation while GalR3 depletion significantly inhibited cell proliferation $(\mathrm{P}<0.05$; Fig. 2B).

The regulatory roles of galanin and GalRs on the profibrogenic features of HSCs were further studied by measuring the expression of key proteins. As shown in Fig. 2C-E, compared with the corresponding controls, galanin (100 nmol/l) significantly inhibited TGF- $\beta 1$ and $\alpha$-SMA protein expression while stimulating PPAR- $\gamma$ expression $(\mathrm{P}<0.01)$. GalR2 knockdown in HSC-T6 cells did not markedly affect TGF- $\beta 1$ and $\alpha$-SMA protein expression but significantly increased PPAR- $\gamma$ expression $(\mathrm{P}<0.05)$ compared with that in the control group. By contrast, GalR3 knockdown attenuated TGF- $\beta 1(\mathrm{P}<0.05)$ and $\alpha$-SMA $(\mathrm{P}<0.01)$ protein expression while increasing PPAR- $\gamma$ expression $(\mathrm{P}<0.01)$ compared with the respective levels in the control group. When considered together, the data indicate that galanin inhibits HSC proliferation and suppresses the profibrogenic features of these cells. Its regulatory roles are likely mediated by GalR2.

\section{Discussion}

In the current study, it was demonstrated that GalR2 expression is undetectable in quiescent HSCs but induced in activated HSCs, whereas galanin and GalR3 are expressed in both quiescent and activated HSCs. Galanin (100 nmol/l) significantly inhibited cell proliferation, $\alpha$-SMA and TGF- $\beta 1$ expression and stimulated PPAR $-\gamma$ expression in activated HSCs. The results suggest the effects of galanin might be mediated by GalR2.

Activated HSCs transdifferentiate into myofibroblasts, which then produce massive amounts of ECM proteins. The activated HSCs adopt a smooth muscle myofibroblast-like phenotype that is characterized by the expression of $\alpha$-SMA (11). Based on the fact that galanin can inhibit the proliferation of PC12 cells (12), counteracts leptin, is involved in fibrogenesis, and undergoes expression and secretion in rat adipose tissue and 3T3-L1 adipocytes $(5,6)$, it was proposed that galanin might inhibit the activation and proliferation of HSCs. The expression of galanin and GalRs in HSCs was therefore investigated and confirmed in this study (Fig. 1). Cell proliferation assay results indicated that galanin also inhibits the proliferation of HSCs (Fig. 2A). Moreover, as a characteristic of activated HSCs, $\alpha$-SMA protein was also downregulated when HSC-T6 cells were treated with galanin (Fig. 2C).

A biphasic inhibitory effect of galanin, occurring at low concentrations (100-1,000 nmol/l) and disappearing at 
A

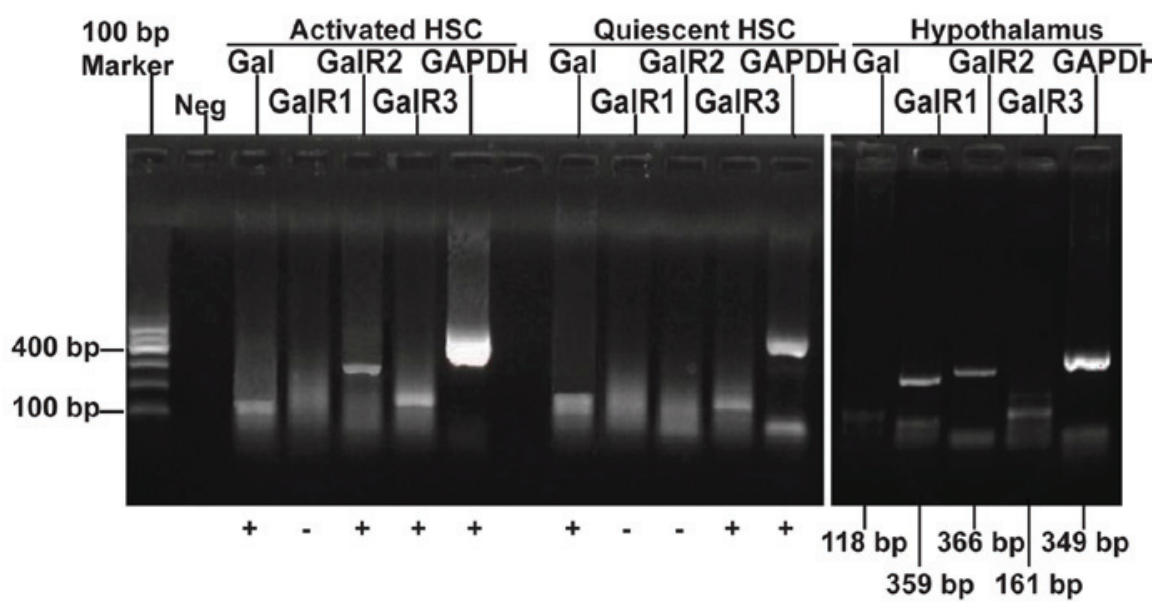

B
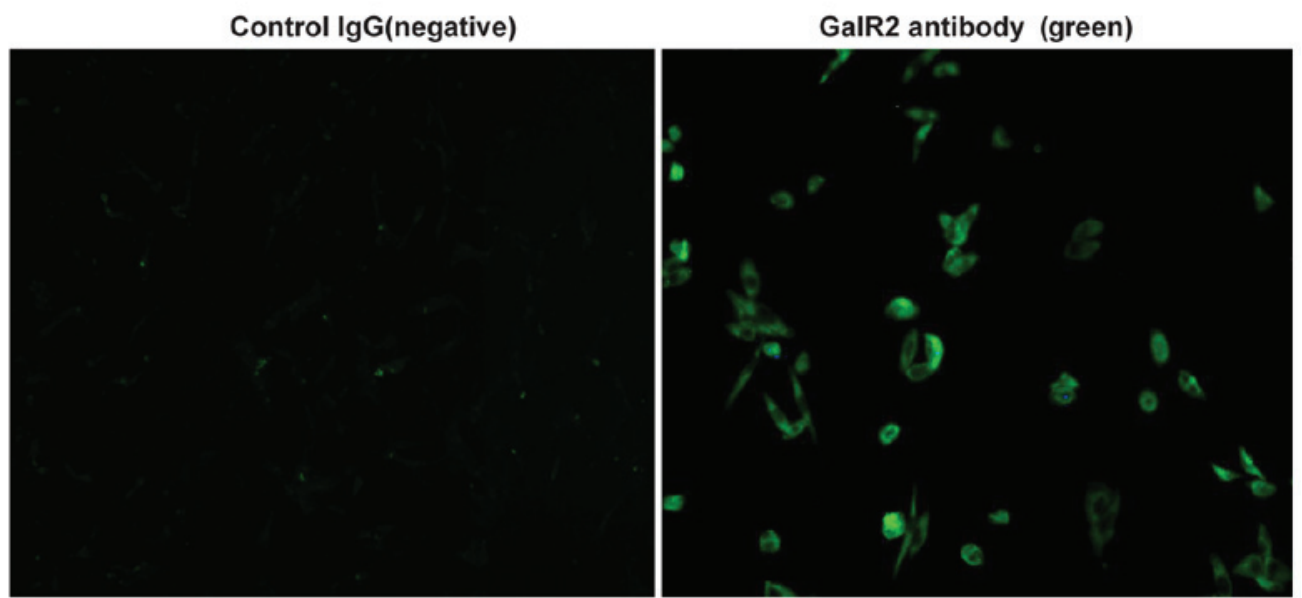

Figure 1. Galanin and GalRs are differentially expressed in quiescent and activated HSCs. (A) The gene expression of galanin and GalRs was detected using RT-PCR. Rat hypothalamic RNA was used as the positive control. (B) Immunofluorescent staining of GalR2 protein in activated HSCs. Cells were stained with the anti-GalR2 antibody and FITC-labeled secondary antibody (right image; positive staining shown in green) or the secondary antibody only (left image; negative control), respectively. Magnification, x100. GalR, galanin receptor; HSC, hepatic stellate cell; RT-PCR, reverse transcription-polymerase chain reaction; FITC, fluorescein isothiocyanate.

a higher concentration $(10,000 \mathrm{nmol} / \mathrm{l})$, was observed. The mechanism of this biphasic inhibitory effect is unclear. It is speculated that such a high concentration of galanin will result in the saturation of GalR2 and GalR3. The saturation of these two receptors may lead to a biological effect totally different from the variable activation of GalR2 and GalR3 observed at a lower concentration of galanin (13). Other biological processes such as receptor endocytosis may also be involved. Indeed, a similar pharmacological profile has been reported for other peptides in several types of cells, including cardiac fibroblasts (13). Although the underlying mechanism is unknown, others also speculate that it might be associated with the activation of multiple receptors or enzymes (13).

Inhibition of HSC activation and proliferation by galanin may be associated with the downregulation of TGF- $\beta 1$ protein. TGF- $\beta 1$ is derived from paracrine and autocrine sources, and is the most potent fibrogenic cytokine in liver (14). Quiescent HSCs induced by TGF- $\beta 1$ transdifferentiate into myofibroblasts that secrete ECM (15). HSCs generate fibrosis by increasing cell number and matrix production per cell (11). Inhibition of HSC proliferation and downregulation of TGF- $\beta 1$ expression may contribute to the control of liver fibrosis $(8,14)$.
Activated reversion of HSCs is another interesting process that was investigated in the present study. PPAR- $\gamma$ is highly expressed in quiescent HSCs where it reinforces the adipogenic property of the cells (16). The expression of PPAR $-\gamma$ is markedly reduced during HSC activation. Forced re-expression of PPAR- $\gamma$ leads to a partial reversal of the cells' pro-fibrogenic phenotypes, including the loss of collagen 1 expression, prevention of TGF- $\beta 1$ signaling, reduction of proliferation capacity, re-expression of adipogenic transcription factors and re-uptake of lipid into intracellular vesicles (16-18). In the present study, it was demonstrated that galanin upregulates the expression of PPAR- $\gamma$ protein in activated HSCs. Indeed, HSCs are a kind of lipocyte and galanin is also present in adipocytes $(18,19)$. Since galanin exerts its effects through GalRs, and GalR2 expression is induced during HSC activation, whether GalR2 has regulatory roles in HSCs was then considered.

To investigate this, GalR2 and GalR3 were depleted in HSC-T6 cells using siRNA. The results suggest that GalR2 may mediate the function of galanin in HSCs. Following the knockdown of GalR 2 by siRNA, the activation of GalR3 by galanin does not influence these effects of galanin on HSCs. However, activation of GalR2 alone by galanin following the 
A

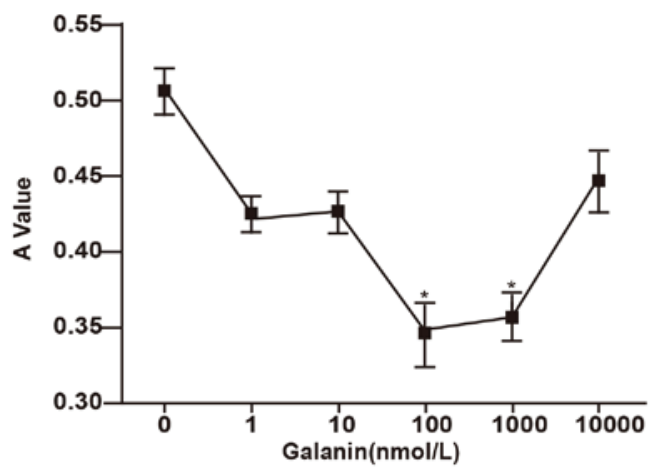

C

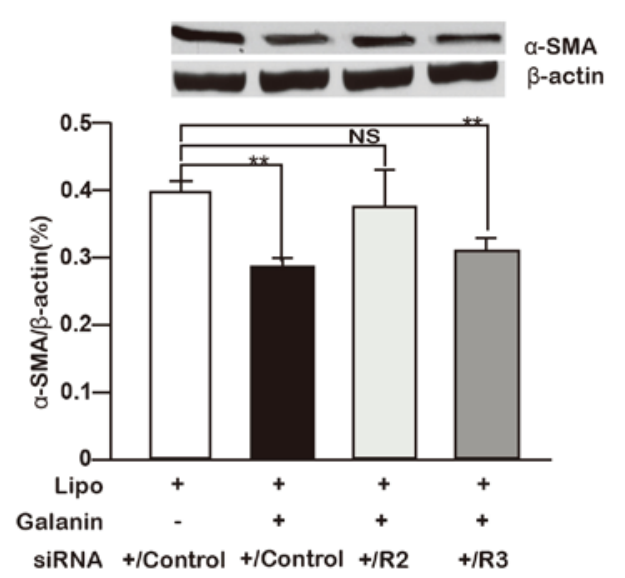

B

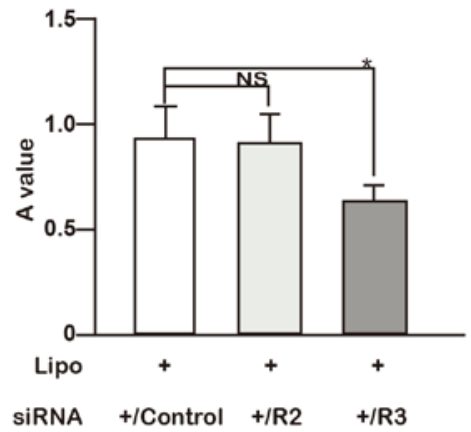

D

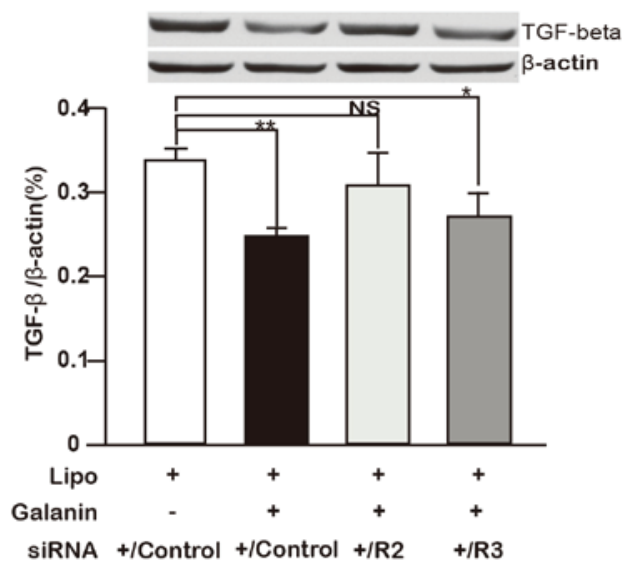

$\mathbf{E}$

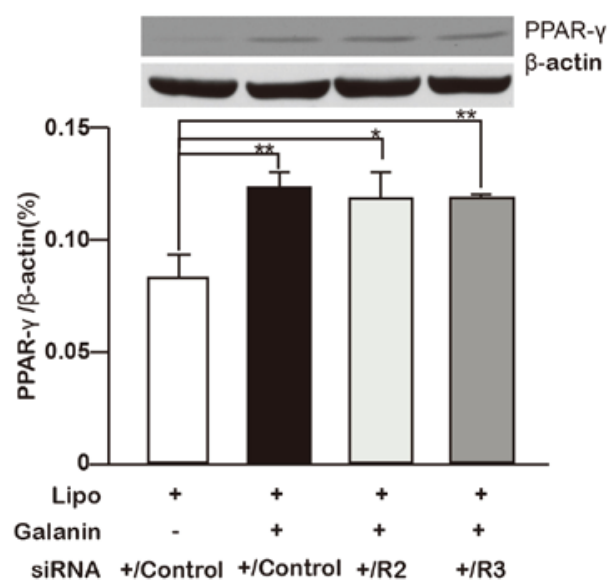

Figure 2. Galanin and GalRs regulate HSC proliferation and profibrogenic gene expression. (A) HSC-T6 cells were treated with different concentrations of galanin $(1-10,000 \mathrm{nmol} / \mathrm{l})$ and the cell proliferation was measured with an MTT assay. The A value measured after MTT administration represents the viable cell number. "P<0.05 vs. control (0 nmol/l). (B) HSC-T6 cells were treated with siRNA against GalR2 and GalR3, or scrambled siRNA (control siRNA). Cell proliferation is shown as the rate relative to the controls. "P<0.05. (C-E) Effects of galanin $(100 \mathrm{nmol} / \mathrm{l})$ treatment and siRNA knockdown of GalR2, GalR3 or control siRNA on (C) $\alpha$-SMA, (D) TGF- $\beta 1$ and (E) PPAR- $\gamma$ protein expression in HSC-T6 cells are shown. The proteins detected by western blotting were quantified with image analysis software and the relative expression levels of $\alpha$-SMA, TGF- $\beta 1$ and PPAR- $\gamma$ to $\beta$-actin are shown as bar graphs. Western blot images are shown on top of the bar graphs. ${ }^{*} \mathrm{P}<0.05,{ }^{* *} \mathrm{P}<0.01$. GalR, galanin receptor; R2, GalR2; R3, GalR3; HSC, hepatic stellate cell; A, absorbance; siRNA, small interfering RNA; Lipo, lipofectamine; NS, not significant; $\alpha$-SMA, $\alpha$-smooth muscle actin; TGF- $\beta$, transforming growth factor- $\beta$; PPAR- $\gamma$, peroxisome proliferator-activated receptor- $\gamma$.

knockdown of GalR3 inhibits HSC proliferation and TGF- $\beta 1$ and $\alpha$-SMA expression, in addition to inducing PPAR $\gamma$ expression. This result is similar to the findings made by Tofighi et al (12). They found galanin decreases the proliferation of $\mathrm{PC} 12$ cells and induces cell apoptosis via its subtype 2 receptor. GalR2 functions through several different classes of $\mathrm{G}$ proteins that activate diverse intracellular pathways.
The most frequently reported pathway involves activation of the $\mathrm{Gq} / 11$-type $\mathrm{G}$ protein, which leads to the hydrolysis of inositol phosphate and activation of protein kinase $\mathrm{C}$ (PKC) and phosphoinositide 3-kinase (PI3K) (19-21). The P13K-Akt/protein kinase B pathway and PKC family members activate the Ras-mitogen-activated protein kinase pathway, which is involved in platelet-derived growth factor 
signaling, one of the most well-characterized pathways of HSC activation $(22,23)$.

In summary, the results of the present study indicate that galanin inhibits HSC activation and suppresses their profibrogenic features. The underlying mechanisms may involve inhibition of HSC proliferation, reduction of TGF- $\beta 1$ expression and induction of PPAR $\gamma$ expression. These biological functions of galanin might be mediated by GalR2. Therefore, galanin is a promising endogenous factor involved in the inhibition of liver fibrosis. Additional studies using animal models are required to gain further insight into the biological effects of galanin in fibrosis.

\section{Acknowledgements}

This study was supported by grants from the National Natural Science Foundation of China (grant no. 81170410 for Dr Yuanwen Chen and grant no. 81260081 for Dr Yongnian Ding) and sponsored by the New Talented Young Medical Specialist Cultivating Program of Shanghai (grant no. XYQ2011010 for Dr Yuanwen Chen), the Key Research Program for Colleges and Universities of Xinjiang Uygur Autonomous Region (grant no. XJEDU2012I001 for Dr Yongnian Ding), and by the State Key Development Program for Basic Research of China (grant no. 2012CB517501 for Dr Jiangao Fan).

\section{References}

1. Tatemoto K, Rökaeus A, Jörnvall H, McDonald TJ and Mutt V: Galanin - a novel biologically active peptide from porcine intestine. FEBS Lett 164: 124-128, 1983.

2. Gundlach AL, Burazin TC and Larm JA: Distribution, regulation and role of hypothalamic galanin systems: Renewed interest in a pleiotropic peptide family. Clin Exp Pharmacol Physiol 28: 100-105, 2001.

3. Poritsanos NJ, Mizuno TM, Lautatzis ME and Vrontakis M: Chronic increase of circulating galanin levels induces obesity and marked alterations in lipid metabolism similar to metabolic syndrome. Int J Obes (Lond) 33: 1381-1389, 2009.

4. Barrachina MD, Martínez V, Wei JY and Taché Y: Leptin-induced decrease in food intake is not associated with changes in gastric emptying in lean mice. Am J Physiol 272: R1007-R1011, 1997.

5. Li RY, Song HD, Shi WJ, Hu SM, Yang YS, Tang JF, Chen MD and Chen JL: Galanin inhibits leptin expression and secretion in rat adipose tissue and 3T3-L1 adipocytes. J Mol Endocrinol 33: 11-19, 2004

6. Wang J,Leclercq I, Brymora JM, Xu N, Ramezani-Moghadam M, London RM, Brigstock D and George J: Kupffer cells mediate leptin-induced liver fibrosis. Gastroenterology 137: 713-723, 2009.

7. Saxena NK, Saliba G, Floyd JJ and Anania FA: Leptin induces increased alpha2(I) collagen gene expression in cultured rat hepatic stellate cells. J Cell Biochem 89: 311-320, 2003.
8. Dooley S, Delvoux B, Streckert M, Bonzel L, Stopa M, ten Dijke P and Gressner AM: Transforming growth factor beta signal transduction in hepatic stellate cells via Smad2/3 phosphorylation, a pathway that is abrogated during in vitro progression to myofibroblasts. TGFbeta signal transduction during transdifferentiation of hepatic stellate cells. FEBS Lett 502: 4-10, 2001.

9. Vogel S, Piantedosi R, Frank J, Lalazar A, Rockey DC, Friedman SL and Blaner WS: An immortalized rat liver stellate cell line (HSC-T6): A new cell model for the study of retinoid metabolism in vitro. J Lipid Res 41: 882-893, 2000.

10. Chen Y, Pat B, Zheng J, Cain L, Powell P, Shi K, Sabri A, Husain A and Dell'italia LJ: Tumor necrosis factor-alpha produced in cardiomyocytes mediates a predominant myocardial inflammatory response to stretch in early volume overload. J Mol Cell Cardiol 49: 70-78, 2010.

11. Benyon RC and Arthur MJ: Extracellular matrix degradation and the role of hepatic stellate cells. Semin Liver Dis 21: 373-384, 2001.

12. Tofighi R, Joseph B, Xia S, Xu ZQ, Hamberger B, Hökfelt T and Ceccatelli S: Galanin decreases proliferation of PC12 cells and induces apoptosis via its subtype 2 receptor (GalR2). Proc Natl Acad Sci USA 105: 2717-2722, 2008.

13. Rhaleb NE, Peng H, Harding P, Tayeh M, LaPointe MC and Carretero OA: Effect of $\mathrm{N}$-acetyl-seryl-aspartyl-lysyl-proline on DNA and collagen synthesis in rat cardiac fibroblasts. Hypertension 37: 827-832, 2001.

14. Inagaki $\mathrm{Y}$ and Okazaki I: Emerging insights into transforming growth factor beta Smad signal in hepatic fibrogenesis. Gut 56: 284-292, 2007.

15. Breitkopf K, Godoy P, Ciuclan L, Singer MV and Dooley S: TGF-beta/Smad signaling in the injured liver. Z Gastroenterol 44 : 57-66, 2006.

16. Hazra S, Miyahara T, Rippe RA and Tsukamoto H: PPAR gamma and hepatic stellate cells. Comp Hepatol 3 (Suppl 1): S7, 2004.

17. Tsukamoto H, She H, Hazra S, Cheng J and Miyahara T: Anti-adipogenic regulation underlies hepatic stellate cell transdifferentiation. J Gastroenterol Hepatol 21 (Suppl 3): S102-S105, 2006.

18. She H, Xiong S, Hazra S and Tsukamoto H: Adipogenic transcriptional regulation of hepatic stellate cells. J Biol Chem 280: 4959-4967, 2005

19. Fathi Z, Battaglino PM, Iben LG, Li H, Baker E, Zhang D, McGovern R, Mahle CD, Sutherland GR, Iismaa TP, et al: Molecular characterization, pharmacological properties and chromosomal localization of the human GALR2 galanin receptor. Brain Res Mol Brain Res 58: 156-169, 1998.

20. Lehmann JM, Kliewer SA, Moore LB, Smith-Oliver TA, Oliver BB, Su JL, Sundseth SS, Winegar DA, Blanchard DE, Spencer TA and Willson TM: Activation of the nuclear receptor LXR by oxysterols defines a new hormone response pathway. J Biol Chem 272: 3137-3140, 1997.

21. Wang S, Hashemi T, Fried S, Clemmons AL and Hawes BE: Differential intracellular signaling of the GalR1 and GalR2 galanin receptor subtypes. Biochemistry 37: 6711-6717, 1998.

22. Wong L, Yamasaki G, Johnson RJ and Friedman SL: Induction of beta-platelet-derived growth factor receptor in rat hepatic lipocytes during cellular activation in vivo and in culture. J Clin Invest 94: 1563-1569, 1994.

23. Kelly JD, Haldeman BA, Grant FJ, Murray MJ, Seifert RA, Bowen-Pope DF, Cooper JA and Kazlauskas A: Platelet-derived growth factor (PDGF) stimulates PDGF receptor subunit dimerization and intersubunit trans-phosphorylation. J Biol Chem 266: 8987-8992, 1991. 